\title{
Prototype Sistem Kendali Jarak Jauh Air Conditioner Berbasis Arduino dan Wifi
}

\author{
Hafiz Khairunsyah $^{* 1}$, Solikhun ${ }^{2}$, Zulaini Masruro Nasution ${ }^{3}$, \\ Bahrudi Efendi Damanik ${ }^{4}$, Iin Parlina ${ }^{5}$
}

\author{
1,2,3,4,5 Teknik Informatika, STIKOM Tunas Bangsa Pematangsiantar, Indonesia \\ Email: ${ }^{1}$ khafiz502@gmail.com, ${ }^{2}$ Solikhun@amiktunasbangsa.ac.id, ${ }^{3}$ zulen_nasution04@ymail.com, \\ ${ }^{4}$ bahrudiefendi@gmail.com, ${ }^{5}$ iin@amiktunasbangsa.ac.id
}

\begin{abstract}
Abstrak
Kebutuhan akan sistem pengendalian jarak jauh semakin meningkat dimana perpindahan dan pergerakan manusia semakin luas dan cepat, terutama di kota besar aktifitas setiap individu masyarakat sangatlah padat dengan berbagai macam pekerjaannya, tentunya memakan waktu dari pagi hingga malam hari. Akibatnya banyak kegiatan di rumah tangga, dan aktivitas kerja yang tertunda, seperti menghidupkan atau mematikan alat-alat elektronik contohnya $A C$ di setiap ruangan saat pagi dan malam hari. Selama ini masyarakat dapat mengendalikan sesuatu dari jarak jauh dengan menggunakan Remote Control yang berbasis Infra Red, kemudian dengan saklar yang melalui kabel, akan tetapi pengendalian tersebut dibatasi oleh jarak jangkauan. Agar cakupan jarak semakin luas dan mudah salah satu solusinya menggunakan ponsel sebagai Remote Control. prototype dari sistem semacam itu diwujudkan dengan memanfaatkan Arduino sebagai perangkat pengendali, jaringan wifi sebagai jalur komunikasi, dan smartphone atau komputer sebagai perangkat penyedia user interface. Langkah untuk mewujudkannya mengikuti tahap-tahap pada metode prototyping, yang terdiri atas analisis kebutuhan, pengembangan prototype, dan pengujian prototype. Rangkaian hardware yang dibangun terdiri atas Arduino yang dilengkapi dengan $I R$ receiver, IR transmitter, LDR, dan sensor suhu. Software yang digunakan adalah Arduino IDE, Notepad++, Apache, Mysql, dan PHP. Penggunaan sistem Arduino untuk menggontrol AC menggunakan smartphone dengan menggunakan aplikasi Blynk. Adanya alat tersebut dapat mempermudah pemilik rumah dan restoran mengontrol $A C$ menggunakan smartphone Sistem ini akan mempermudah pegawai dalam mengelola pengoperasian $A C$ di setiap ruang PIZZA HOUSE, dan sekaligus dapat meningkatkan efisiensi penggunaan listrik.
\end{abstract}

Kata kunci: Air Conditioner, Arduino, Remote Control, Wifi

\begin{abstract}
The need for a remote control system is increasing where the movement and movement of people is getting wider and faster, especially in big cities the activities of each individual community are very dense with various kinds of work, of course it takes time from morning to night. As a result, many activities in the household and work activities are delayed, such as turning on or off electronic devices such as air conditioning in every room in the morning and at night. So far, people can control something remotely by using a Remote Control based on Infra Red, then with a switch via cable, but this control is limited by the range. In order for wider and easier distance coverage, one solution is to use a cellphone as a Remote Control. The prototype of such a system is realized by using Arduino as a control device, a wifi network as a communication line, and a smartphone or computer as a user interface provider device. The steps to make it happen follow the stages in the prototyping method, which consists of needs analysis, prototype development, and prototype testing. The hardware set consists of an Arduino equipped with an $I R$ receiver, IR transmitter, LDR, and temperature sensor. The software used is the Arduino IDE, Notepad ++, Apache, Mysql, and PHP. The use of the Arduino system to control the air conditioner using a smartphone using the Blynk application. The existence of this tool can make it easier for home and restaurant owners to control the air conditioner using a smartphone. This system will make it easier for employees to manage the operation of the air conditioner in each PIZZA HOUSE room, and at the same time can increase the efficiency of electricity use.
\end{abstract}

Keywords: Air Conditioner, Arduino, Remote Control, Wifi 


\section{PENDAHULUAN}

Meningkatnya perkembangan teknologi pada saat ini, kebutuhan akan teknologi sangatlah di perlukan untuk segala aktifitas pekerjaan terutama di kota besar yang begitu padat masyarakatnya, dan aktifitas dari pagi hingga malam hari banyak yang tertunda, akibatnya banyak memakan waktu yg cukup lama seperti contoh meghidupkan/mematikan alat-alat elektronik contohnya $A C$ di setiap ruangan saat pagi dan malam hari.

Penerapan teknologi pada peralatan rumah tangga yang setiap harinya dipakai oleh masyarakat secara berulang-ulang dapat mempermudah pekerjaan. Sudah banyak peralatan rumah tangga yang telah dimodernisasi. Untuk menyambung dan memutus arus listrik pada peralatan rumah tangga seperti lampu, kipas angin dan banyak yang lainnya biasanya kita harus berjalan ke tempat saklar itu dipasang. Hal ini tidak nyaman bagi beberapa kelompok masyarakat seperti lansia, penyandang disabilitas, dan masyarakat yang tinggal dalam rumah bertingkat. Dalam mempermudah masyarakat untuk mengendalikan dan memonitoring peralatan rumah tangga tersebut dari jarak jauh ialah dengan menekan tombol pada remote (Studi et al., 2021).

Selama ini aktifitas yang di lakukan masih secara local dan belum mengetahui adanya pengendalian yang begitu signifikan dalam mengendalikan sesuatu, seperti mengendalikan alat-alat elektronik yang di batasi oleh jarak tertentu. Oleh karena itu, dilakukan kegiatan pembangunan sebuah Prototype aplikasi sistem AIR CONDITIONER (AC) yang dibangun di platform Android.

Untuk membantu berjalannya sistem ini, terdapat beberapa refreferensi yang dingunakan untuk penulis sebagai rujukan, Arduino adalah alat untuk membuat sistem aplikasi yang interaktif yang di rancang untuk mempermudah dalam pengerjaannya, tetapi para ahli masih fleksibel dalam mengembangkan proyek-proyek yang akan dikembangkannya. dan arduino terdiri atas dua bagian, yaitu hardware dan software. Sistem pengendaliannya menggunakan jaringan internet sebagai pengiriman intruksi dalam sistem pengendalian, yang membuat berbeda dari sistem pengendalian sebelumnya (Arsada, 2017).

Aktivitas yang dilaksanakan di setiap ruangan PIZZA HOUSE selalu menggunakan peralatan elektronik seperti lampu, kipas angin, $A C$ (Air Conditioner), dan proyektor $L C D$, yang dalam pengoperasiannya masih dilakukan secara lokal melalui remote control yang terdapat di dalam setiap ruangan. Mengingat banyaknya ruangan di PIZZA HOUSE, cara lama itu dapat memberatkan karyawan yang bertugas untuk mengelola peralatan tersebut. Ketika aktifivitas telah selesai, sering kali terlihat peralatan tersebut masih dalam keadaan hidup. Hal ini dapat menyebabkan penggunaan listrik yang tidak efisien. Kenyataan ini memunculkan ide untuk membuat sistem yang dapat membantu pekerjaan dengan mudah megelolah alat-alat elektronik tersebut. Dan jaringan wifi adalah sarana jaringan internet, relay adalah sebagai intruksi yang akan di terima oleh arduino dalam pengendaliannya , dan untuk mengendalikannya di butuhkan sebuah sistem aplikasi yang bernama aplikasi blynk yang bisa di unduh di smartphone maupun komputer. Hal ini yang menjadi latar belakang untuk melakukan penelitian yang berjudul "PROTOTYPE SISTEM KENDALI JARAK JAUH PERANGKAT AIR CONDITIONER (AC) BERBASIS ARDUINO DAN WIFT".

\subsection{Air Conditioner $(A C)$}

Air Conditioner adalah suatu rangkaian mesin yang berfungsi sebagai pendingin udara sekitar yang berada di mesin tersebut. Dan mesin yang mensirkulasikan gas refrigerant berada pada pipa yang di tekan atau di hisap pada kompresor. Dan untuk mengendalikan mesin tersebut di perlukan remote control sebagai media untuk mengatur suhu .

Pada dasarnya prinsip kerja Air Conditioner (AC) sama dengan refrigerasi, namun Air Conditioner (AC) tidak berfungsi sebagai pendingin saja, tetapi harus dapat menghasilkan udara nyaman. Hal ini dilakukan dengan jalan pengontrolan terhadap kondisi fisika dan kimiawi udara yang meliputi suhu, kelembaban, Gerakan udara, tekanan udara, debu, bakteri, bau, gas beracun dan ionisasi (Sumpena et al., 2012). 


\subsection{Arduino Uno}

Kemajuan Teknologi Mikrokontroler saat ini sudah sampai pada penggunaan Mikrokontroller dengan berbagai platform open source seperti Arduino Uno. Untuk mengaktifkan Arduino Uno hanya langsung di hubungkan ke komputer dengan kabel USB atau menggunakan adaptor AC ke DC serta menggunakan baterai. Untuk dayanya (Abimanyu et al., 2021).

Arduino adalah pengendali mikro sigle-bord yang bersifat terbuka, di turukan Wiring platform, yang di rancang untuk memudahkan penggunaan elektronik dalam berbagai bidang. Arduino digunakan untuk menerima masukan dari switch atau sensor dan mengontrol berbagai macam alat elektronik, motor dan output yang lainnya.

Bentuk Arduino Uno dapat di lihat pada gambar di bawah ini.

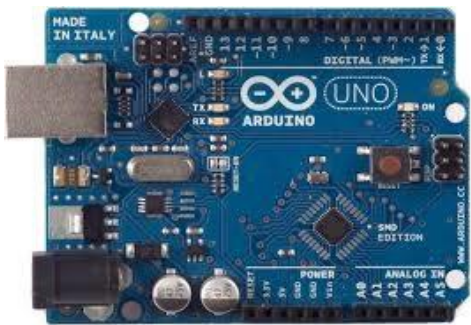

Gambar 1. Arduino Uno

\subsection{Relay}

Relay adalah Saklar (Switch) yang dioperasikan secara listrik dan merupakan komponen Electromechanical (Elektromekanikal) yang terdiri dari 2 bagian utama yakni Elektromagnet (Coil) dan Mekanikal (seperangkat Kontak Saklar/Switch). Relay menggunakan Prinsip Elektromagnetik untuk menggerakkan Kontak Saklar sehingga dengan arus listrik yang kecil (low power) dapat menghantarkan listrik yang bertegangan lebih tinggi (Saleh \& Haryanti, 2017).

Relay merupakan komponen elektronika berupa Saklar (Switch) elektrik yang dioperasikan secara listrik dan merupakan komponen Electromechanical (Elektromekanikal) yang terdiri dari 2 (dua) bagian utama yakni Elektromagnet (Coil) dan mekanikal.

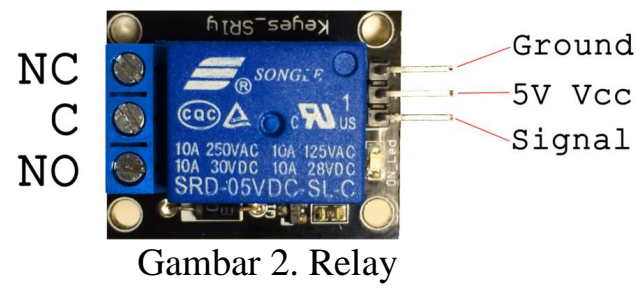

\subsubsection{Prinsip Kerja Relay}

Pada dasarnya, Relay terdiri dari 4 komponen dasar yaitu:

1. Electromagnet (Coil)

2. Armature

3. Switch Contact Point (Saklar)

4. Spring

\subsubsection{Fungsi-fungsi dan Aplikasi Relay} adalah:

Beberapa fungsi Relay yang telah umum diaplikasikan kedalam peralatan Elektronika diantaranya 1. Relay digunakan untuk menjalankan Fungsi Logika (Logic Function). 
2. Relay digunakan untuk memberikan Fungsi penundaan waktu (Time Delay Function).

3. Relay digunakan untuk mengendalikan Sirkuit Tegangan tinggi dengan bantuan dari Signal Tegangan rendah.

4. Ada juga Relay yang berfungsi untuk melindungi Motor ataupun komponen lainnya dari kelebihan Tegangan ataupun hubung singkat (Short).

\subsection{NodeMCU}

NodeMCU pada dasarnya adalah pengembangan dari ESP 8266 dengan firmware berbasis e-Lua. Pada NodeMcu dilengkapi dengan micro usb port yang berfungsi untuk pemorgaman maupun power supply. Selain itu juga pada NodeMCU di lengkapi dengan tombol push button yaitu tombol reset dan flash. NodeMCU adalah platform IOT open source. NodeMCU firmware yang berjalan pada ESP8266 Wi-Fi SoC yang dirancang oleh Sistem Espressif yang didasarkan pada Modul ESP-12. Istilah "NodeMCU" secara default mengacu pada firmware DevKit. Firmware menggunakan Bahasa scripting Lua dan dapat didigunakan dalam beberapa projek seperti lua-cjson, dan spiff (Sentanu et al., 2021).

Gambar NodeMCU dapat dilihat pada gambar berikut.

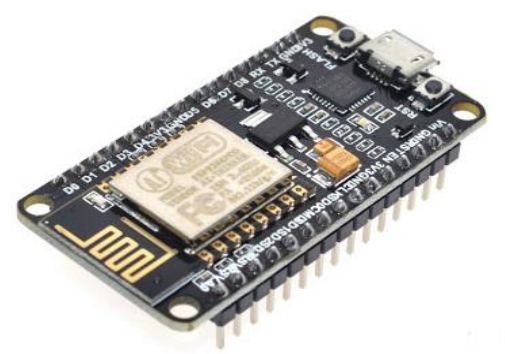

Gambar 3. NodeMCU

\subsection{Kabel Jumper}

Kabel jumper adalah kabel elektrik yang memiliki pin konektor di setiap ujung ya dan memunginkan untuk menghubungkan dua komponen yang melibatkan arduinno". Dan inti kegunaan kabel jumper ini adalah sebagai konduktor listrik untuk menyambungkan rangkaian listrik. Dalam penelitian ini kabel jumper di gunakan untuk menghubungkan beberapa alat Arduino seperti Arduino Uno ke NodeMcu dan menghubungkan ke Relay (Mutu et al., 2019). Kabel jumper dapat dilihat pada gambar dibawah ini.

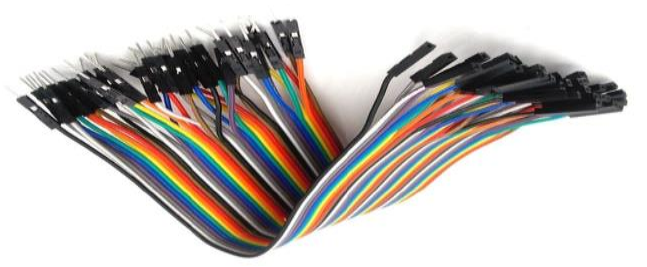

Gambar 4. Kabel Jumper

\subsection{Arduino IDE}

Arduino IDE merupakan software yang dapat digunakan untuk membuat kode program dilengkapi dengan fitur pada toolbar memiliki fungsi yang dapat membantu dalam menghubungkan program dengan mikronontroler arduino. Program yang dibuat dengan arduino IDE disebut dengan sketches. File sketches yang dibuat selanjutnya akan disimpan dengan menggunakan format ino. Berbagai fitur yang dapat digunakan dalam membuat kode program seperti copy, paste, cut, searching dan replace text (Mikrokontroller \& Berbasis, 2016). 


\section{METODE PENELITIAN}

Metode penelitian ini menggunakan arduino, nodemcu, dan relay pada objek penelitian. Pada penelitian ini membahas tentang bagaimana cara mengontrol Air Conditioner $(A C)$ jarak jauh.

\subsection{Rancangan Penelitian}

Sistem kendali jarak jauh air conditioner berbasis Arduino dan wifi, penulis membuat beberapa tahap perancancangan, mulai dari pengambilan data sampai dengan pengolahan yang akan dibuat sehingga hasil outputnya lebih jelas.

Gambar Rancangan penelitian dapat dilihat ada gambar berikut.

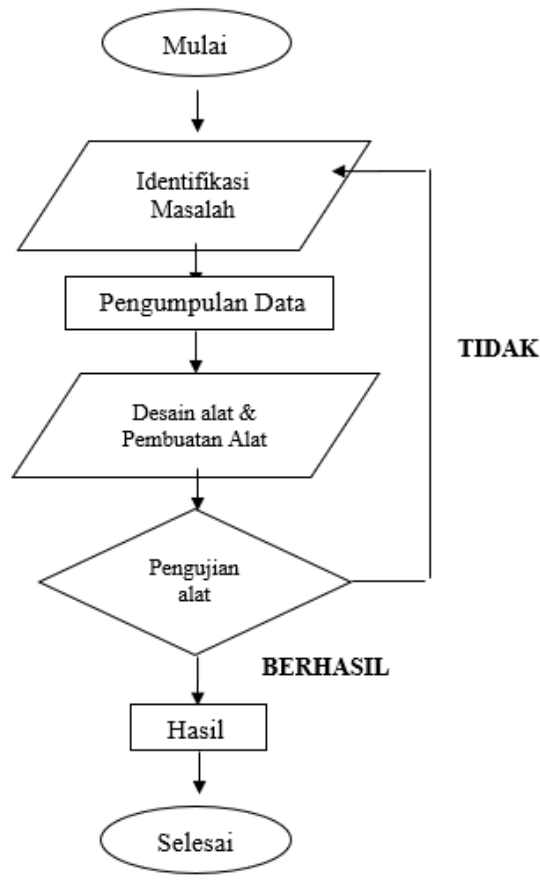

Gambar 5. Rangkaian Penelitian

Penjelasan Flowchart penelitian yang dibuat oleh penulis pada gambar di atas sebagai berikut.

1. IdentifikasiMasalah

Pengenalan suatu masalah dan tahap awal dalam proses penelitian. Permasalahan penelitian ini yaitu saat merancang sebuah alat untuk membantu pengguna dalam mengontrol $A C$.

2. Pengumpulan Data

Data pada penelitian ini diperoleh dari rumah dengan mengambil sampel data dari dinding ke dinding rumah.

3. Pengolahan Data

Pada langkah ini data-data yang sudah di dapat dari studi identifikasi masalah dan pengumpulan data yang kemudian diolah untuk menyelesaikan permasalahan yang di temukan.

4. Studi Literatur

Metode pengumpulan data yang menggunakan beberapa jurnal sebagai referensi untuk penulis.

5. Observasi

Metode pengumpulan data dengan mengamati beberapa perumahan, dengan mengambil data dari perumahan warga.

6. Pembuatan Alat

Selanjutnya adalah merancang sebuah alat yang dapat menyelesaikan permasalahan yang di alami.

7. Pengujian Alat

Melakukan pengujian alat dengan cara mematikan atau menghidupkan AC menggunakan smartphone. 
8. Hasil

Menghasilkan alat yang di rancang dan Mengimplementasikan alat yang di buat agar dapat di gunakan.

\subsection{Perancangan Perangkat Keras}

Dalam meringankan perancangan sistem ini maka akan memakai blok diagram untuk tahapan awal dalam proses pembuatannya, dimana blok diagram ini digunakan untuk menampilkan bagaimana cara kerja sistem ini dilakukan secara umum. Sistem rangkaian dapat dilihat pada gambar dibawah ini.

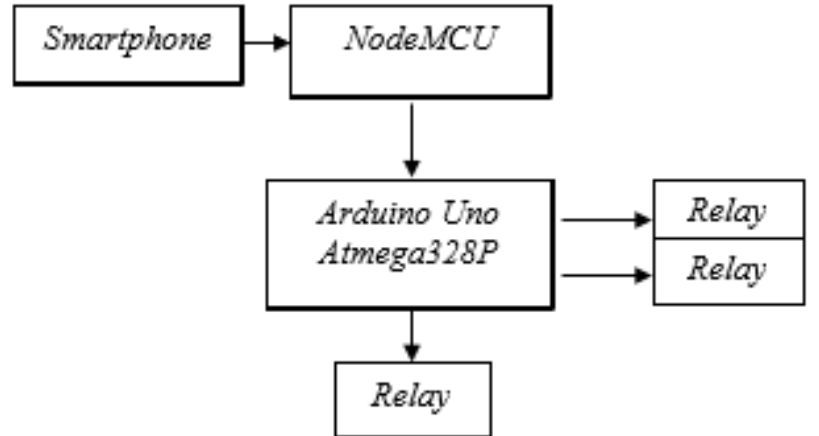

Gambar 6. Blok diagram lain:

Pada Gambar diatas terdapat beberapa komponen perangkat keras prototype alat kendali $A C$, antara

1. Smartphone merupakan komponen yang berfungsi untuk mengendalikan energi $A C$ kerangkaian yang terdapat dalam sistem.

2. NodeMcu dilengkapi dengan micro usb port yang berfungsi untuk pemorgaman maupun power supply.

3. Mikrokontroler merupakan pusat kendali yang berupa sebuah IC Mikrokontroler seri ATMega328p.

4. Relay $5 v$ yang bekerja dengan menggunakan prinsip elektromagnetik, dimana ketika ada arus lemah yang mengalir melalui kumparan inti besi lunak akan menjadi magnet.

\subsection{Cara Kerja Alat}

Cara kerja alat pada penelitian ini adalah sebagai berikut ini:

1. Power On Alat.

2. Arduino berada pada posisi default.

3. Membaca jarak dengan sensor Relay.

4. Mendeteksi hasil dari pembacaan sensor.

5. Hasil akan di tampilkan pada papan Layar LCD.

\section{HASIL DAN PEMBAHASAN}

Pada tahap ini alat yang sudah dirancang selanjutnya akan melalui tahap prototyping dan simulasi. Alat ini akan bekerja sebagai pengontrol kendali jarak jauh untuk mematikan dan menghidupkan perangkat AC, kemudian NodeMcu menerima perintah dari aplikasi Blynk yang sudah di koneksi sebelumnya. NodeMcu akan melakukan penyambungan arus listrik ke AC yang akan di laksanakan oleh relay sebagai pemutus dan penyambung arus listrik ke AC, lalu AC secara otomatis akan mati. Selanjutnya penulis akan menguraikan beberapa tahapan manfaat dari alat yang telah selesai dibuat.

\subsection{Rancangan Rangkaian}

Sebelum menjelaskan prosedur kerja NodeMcu, terlebih dahulu penulis akan menguraikan hasil dari rancangan dalam pembuatan alat yang dapat mengontrol AC secara otomatis dengan menggunakan NodeMcu. Proses perakitan merupakan proses penggabungan antara NodeMcu, Relay, kabel jumper dan 
beberapa komponen pendukung lainnya untuk menyelesaikan alat tersebut.

Adapun skema rangkaian keseluruhan NodeMcu yang terhubung dengan aplikasi Blynk yang terkoneksi wifi dapat dilihat pada Gambar di bawah ini.

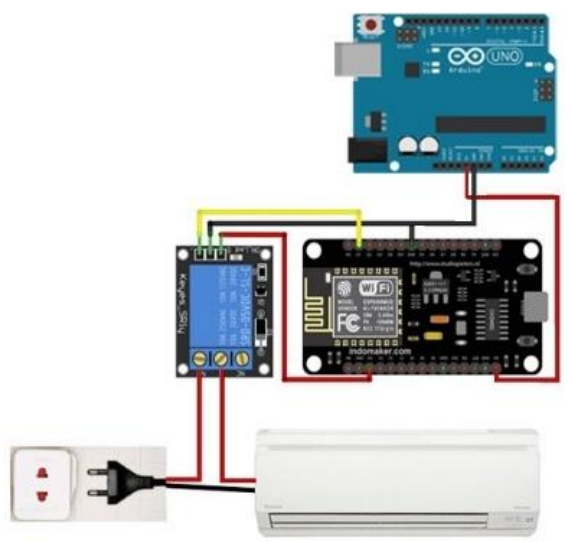

Gambar 7. Rangkaian alat

Berikut pin- pin yang telah terhubung ke pin yang lain dapat dilihat sebagai berikut:

1. Pin VCC pada Relayl dihubungkan ke 3 V NodeMcu.

2. Pin GND pada Relayldihubungkan ke GND Arduino.

3. Pin IN pada Relayl dihubungkan ke D1 NodeMcu dan 5v Arduino.

4. Pin VCC pada Relay2 dihubungkan ke 3 V NodeMcu.

5. Pin GND pada Relay2 dihubungkan ke GND NodeMcu.

6. Pin IN pada Relay2 dihubungkan ke D2 NodeMcu.

Setelah pin pada setiap modul telah terhubung sesuai dengan tempatnya selanjutnya yaitu memasukkan program kedalam rangkaian NodeMcu secara keseluruhan, dengan menggunakan software NodeMcu. Sehingga rangkaian dapat bekerja sesuai dengan apa yang penulis rencanakan sebelumnya.

\subsection{Rangkaian Fisik Alat}

Rangkaian fisik alat protoype system kendali jarak jauh air conditioner berbasisi Arduino dan wifi dapat dilihat pada gambar berikut:

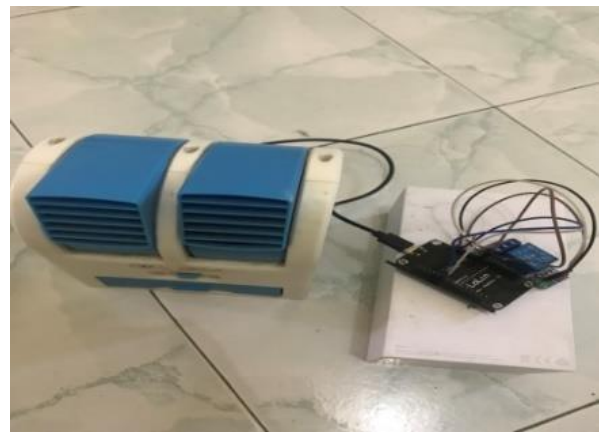

Gambar 8. Rangkaian Fisik alat

\subsection{Pengujian Alat}

Dalam pembahasan ini penulis akan menjelaskan tentang validasi kebutuhan sistem, prosedur kerja sistem, dan kelebihan sistem yang telah dirancang.

Pengujian dimulai dari menyalakan Arduino uno yang dihubungkan ke NodeMcu, yang di hubungkan ke relay. Lalu download aplikasi Blynk, kemudian masuk untuk mendaftar menggunakan Email, lalu buat new project, dan pilihlah salah satu module yang akan anda gunakan maupun aksesoris 
module yang berfungsi sebagai sarana terhubung ke internet, setelah itu drag and drop rancangan proyek anda, kemudian klik Blynk untuk mengirimkan token auth melalui email, dan terakhir cek inbox email anda dan temukan auth token yang dimana ini akan digunakan untuk program yang di download ke module.

Dengan menggunakan penggunaan sistem arduino untuk mengontrol AC menggunakan smartphone yang telah dibuat oleh penulis yang memiliki banyak kelebihan. Alat ini nantinya akan sangat membantu bagi pemilik restoran dalam mengontrol AC tersebut.

\subsection{Prosedur Sistem Kerja}

Setelah proses validasi data dilakukan untuk melakukan pengujian sistem, maka proses selanjutnya adalah penulis akan menjelaskan prosedur kerja sistem yang telah dibuat. Prosedur kerja sistem ini dibuat untuk memastikan apakah seluruh sistem telah berjalan dengan stabil sesuai dengan perancangan yang dibuat oleh penulis.

Pada tahapan awal pengujian sistem ini adalah dengan memberikan daya sebesar 9 volt ke dalam Arduino dan dihubungkan ke NodeMcu Kemudian sambungkan alat ke jaringan internet, pengendalian kontrol jarak jauh menggunakan aplikasi Blynk melalui smartphome untuk menghidupkan dan mematikan AC tersebut. Selanjutnya NodeMcu akan memberikan perintah ke relay sesuai dengan apa yang di perintahkan di pada aplikasi yang di jalankan melalui smartphone. Setelah proses tersebut dilalui maka AC dapat mati maupun hidup, sesuai dengan perintah yang dikirim ke NodeMcu melalui aplikasi Blynk Menggunakan smartphone.

1. Masukan (input)

Dalam perancangan perangkat lunak pada program mikrokontroller arduino uno menggunakan software arduino IDE yang memiliki kesamaan syntaks dengan bahasa pemrograman $C++$ serta memiliki fitur yang dapat mempermudah yaitu library yang berfungsi untuk menulis program ke dalam board arduino.

Setelah merancang alat untuk menghidupkan dan mematikan AC secara otomatis, penulis akan memasukkan perintah kedalam NodeMcu sesuai dengan alat yang dibuat penulis, Untuk memasukkan program ke dalam NodeMcu dibutuhkan sebuah driver USB, Untuk Input data utama pada komponen alat yang dibuat oleh penulis.

2. Pemrosesan (Procces)

NodeMcu yang terhubung ke aplikasi Blynk dapat dengan mudah menghidupkan atau mematikan ac secara otomatis tanpa harus si pemilik restoran menggunakan remote tersebut.

3. Keluaran (Output)

Dalam pembuatan alat untuk menghidupkan dan mematikan AC secara otomatis yang dapat digunakan oleh pemilik restoran, agar pemilik restoran dengan mudah mengontrol AC ketika sedang di luar restoran.

\section{KESIMPULAN}

Berdasarkan hasil uraian dari bab-bab sebelumnya serta hasil yang dilakukan selama melakukan penelitian dan pengujian alat maka dapat disumpulkam bahwasanya system pengendali jarak jauh Air Conditioner berbasis Arduino dan Wifi ini berjalan dengan baik dan sesuai denga napa yang di harapkan, alat ini juga dapat memudahkan pemilik atau orng lain dam mengontrol AC dengan mudah hanya dengan menggunakan smartphone sehingga dapat meminimalisir keborosan arus listrik dan mengurangi resiko arus pendek listrik, namun pada system kerja alat ini penggunaan relay juga memakan waktu yang sedikit lama dan penggunaan kabel jumper yang sering longgar dapat mengganggu peroses pengolahan data.

\section{DAFTAR PUSTAKA}

Abimanyu, D., Anggraini, F., Gunawan, I., \& Parlina, I. (2021). Rancang Bangun Alat Pemantau Kadar pH , Suhu Dan Warna Pada Air Sungai Berbasis Mikrokontroller Arduino Design And Construction Of pH Temperature And Color Monitoring Equipment In Water-Based River On Arduino Microcontroller. 1(6), 235-242. 
Arsada, B. (2017). Aplikasi Sensor Ultrasonik Untuk Deteksi Posisi Jarak Pada Ruang Menggunakan Arduino Uno. Jurnal Teknik Elektro, 6(2), 1-8.

Mikrokontroller, M., \& Berbasis, D. A. N. (2016). No Title. 12.

Mutu, M., Air, K., \& Sekolah, D. I. (2019). Corresponding Author Email : 3(1).

Saleh, M., \& Haryanti, M. (2017). Rancang Bangun Sistem Keamanan Rumah Menggunakan Relay. Jurnal Teknologi Elektro, UniversitasMercu Buana, 8(2), 87-94. https://media.neliti.com/media/publications/141935-ID-perancangan-simulasi-sistempemantauan-p.pdf

Sentanu, I. G. A. A. K., Komang, I. G. A., Djuni, D., Pramaita, N., Program, M., Elektro, S., Teknik, F., \& Udayana, U. (2021). KEBAKARAN HUTAN BERBASIS NODE MCU ESP8266. 8(1), 286-291.

Studi, P., Elektro, T., Teknik, F., \& Udayana, U. (2021). Sistem Notifikasi Switch Berbasis Teknologi Wireless. 8(1), 197-205.

Sumpena, I., Elektro, M., Teknik, D., Elektro, T., \& Suryadarma, U. (2012). Analisa Performansi Sistem Pendingin Ruangan dan Efisiensi Energi Listrik padaSistem Water Chiller dengan Penerapan Metode Cooled Energy Storage. Jurnal Energi Dan Manufaktur, 4(1), 82-89.

Tonara, D. B., \& Dinata, Y. M. (2017). Rancang Bangun Simulasi Palang Pintu Kereta Api Menggunakan Percepatan Berbasis Arduino. 3(1), 23-31. 


\section{Halaman Ini Dikosongkan}

